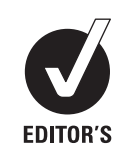

CHOICE

\title{
Cardiovascular abnormalities in Down's syndrome: spectrum, management and survival over 22 years
}

\author{
Claire A Irving, Milind P Chaudhari
}

Department of Paediatric Cardiology, Freeman Hospital, Newcastle upon Tyne, UK

\section{Correspondence to}

Dr Claire Irving, Department of Paediatric Cardiology, Freeman Hospital, Freeman Road, Newcastle upon Tyne NE7 7DN, UK; claire.irving@nuth.nhs.uk

Accepted 28 June 2011 Published Online First 11 August 2011

\begin{abstract}
Background The prevalence of cardiovascular anomalies in Down's syndrome is well described, but there are few data on spectrum, management and outcome. The authors aimed to provide this information for infants with Down's syndrome in a defined population over a 22-year period.

Methods The regional paediatric cardiology database in Newcastle upon Tyne provided information on all cardiovascular anomalies, surgical treatment and outcome. Data was subdivided into two eras, 1985-1995 and 1996-2006, and surgical results and outcomes compared. Data on live births with Down's syndrome were obtained from the Northern Congenital Abnormality Survey (NorCAS). Denominator data on all live births in the region were obtained from UK Statistics.
\end{abstract}

Results In 1985-2006 there were 754,486 live births in the population. 821 infants were live-born with Down's syndrome (1.09 per 1000 live births). 342 (42\%) infants with Down's syndrome had a cardiovascular anomaly. The commonest anomaly was complete atrioventricular septal defect in 125 (37\%) infants. Three patients had univentricular physiology. In 1985-1995, 101/163 (62\%) infants had surgery with 30\% mortality; in 1996-2006, $129 / 180$ (72\%) had surgery with $5 \%$ mortality. One patient underwent Fontan completion. There were two cardiac transplants for cardiomyopathy. One-year survival in Down's syndrome with a cardiovascular anomaly improved from $82 \%$ in $1985-1995$ to $94 \%$ in 1996-2006.

Conclusions The incidence of cardiovascular anomalies in Down's syndrome was $42 \%$. There has been a significant reduction in postoperative mortality and improvement in 1-year survival. Treatment modalities such as single ventricle palliation and cardiac transplantation are now considered in these patients.

\section{INTRODUCTION}

The clinical features of Down's syndrome were first described by John Langdon Down in 1866 with the link to the chromosomal diagnosis of trisomy 21 made by Jerome Lejeune in 1959. It remains the commonest chromosomal abnormality in live born infants ${ }^{1}$ and its association with cardiovascular anomalies is well established. ${ }^{2} 3$ Despite increases in antenatal screening and termination of pregnancy over the last 20 years, there has been no change in the live born prevalence of Down's syndrome in our region, ${ }^{4} 5$ The increase in antenatal diagnosis has likely been offset by the changing maternal age profile in the population, which has shown a threefold increase in the percentage of mothers over 35 years of age at the time of delivery. ${ }^{4}$

\section{What is already known on this topic}

- Cardiovascular anomalies are common in Down's syndrome.

- The commonest cardiovascular anomaly in this population is a complete atrioventricular septal defect.

\section{What this study adds}

- Most cardiovascular anomalies in Down's syndrome are amenable to complete surgical correction in infancy.

- Single ventricle palliation is now considered for selected patients with complex anomalies.

- Cardiac transplantation has been carried out with good outcome.

Surgical management of cardiovascular anomalies has changed considerably over the past two decades, with improving surgical results and reduced mortality especially in the peri-operative period. A wide range of corrective and palliative procedures are now performed for congenital heart disease with excellent postoperative outcome. ${ }^{6}$ However, population based data on the impact of modern surgical interventions on long term outcome in the group of patients with Down's syndrome remain scarce.

In this study we aimed to describe the prevalence and spectrum of cardiovascular anomalies in infants with Down's syndrome in a defined population over a 22-year period, and to assess surgical outcome and survival over time.

\section{METHODS}

This study was based in the North East of England, an area with a resident population of around 3 million and a recent average birth rate of around 34000 live births per year. Data were extracted for the period from January 1985 to December 2006. Details of live births with Down's syndrome (trisomy 21 on karyotype) were obtained from the Northern Congenital Abnormality Survey (NorCAS), a population-based register which has collected data on congenital anomalies in this population since 1985 and is a member of the European Surveillance of Congenital Anomalies. ${ }^{7}$ Denominator data on all live births in the region were obtained from UK Statistics. 
All patients with suspected cardiovascular anomalies in the region are referred to a single paediatric cardiology centre at Freeman Hospital, Newcastle upon Tyne, and data were obtained from the regional paediatric cardiology database on all congenital cardiovascular anomalies in association with Down's syndrome, surgical treatment and outcome. Babies born outside of the region and referred to the paediatric cardiology centre after birth were excluded from the study.

\section{Ethics approval}

NorCAS is one of six linked surveys of fetal and infant health housed at the Regional Maternity Survey Office in Newcastle upon Tyne. The National Information Governance Board has granted exemption from a requirement for consent for inclusion on the NorCAS register. NorCAS has ethics approval $(04 / \mathrm{MRE} 04 / 25)$ to undertake studies involving the use of its data.

\section{RESULTS}

\section{Study population}

In 1985-2006 there were 754486 live births in the population. Eight hundred and twenty one infants were live born with Down's syndrome (prevalence of 1.09 per 1000 live births). Three hundred and forty two infants (42\%) with Down's syndrome had a cardiovascular anomaly (figures 1 and 2).

\section{Spectrum of cardiovascular anomalies}

One hundred and twenty five (37\%) infants had as their primary diagnosis a complete atrioventricular septal defect (CAVSD), 106 (31\%) a ventricular septal defect (VSD), 52 $(15 \%)$ an atrial septal defect (ASD), 22 (6\%) a partial atrioventricular septal defect (PAVSD), 16 (5\%) tetralogy of Fallot, $14(4 \%)$ a patent ductus arteriosus (PDA) and $7(2 \%)$ were in the miscellaneous group (including coarctation of the aorta, pulmonary valve stenosis and vascular ring). The distribution of these diagnoses over time by patient year of birth is shown in figure 3 . Eighty (23\%) had more than one anomaly. The commonest additional diagnoses were ASD and PDA. Median age at diagnosis was 1 month (range 0-203 months).
Three patients were born with single ventricle physiology: unbalanced CAVSD and hypoplastic right ventricle; tricuspid atresia; and pulmonary atresia/intact ventricular septum, respectively.

\section{Management of cardiovascular anomalies}

Two hundred and thirty patients were treated surgically $(67 \%$ of the total group). The surgical results are divided in table 1 into two eras, 1985-1995 and 1996-2006.

In 1985-1995, 101/163 (62\%) infants had surgical correction, of whom 30 died (30\%). Fourteen of these deaths were within the 30-day postoperative period. In 1996-2006, 129/180 (72\%) infants underwent surgery of whom seven died (5\%). Early (30-day) postoperative mortality declined to $1.5 \%$ in the second era (two patients). Six patients required insertion of a permanent pacemaker for postsurgical complete heart block.

In the second decade of study, 17 patients were treated with percutaneous transcatheter device closure of a PDA or ASD.

Three patients with univentricular physiology underwent surgery in the second era of study. One patient with tricuspid atresia underwent pulmonary artery banding and one with pulmonary atresia/intact ventricular septum underwent placement of an aorto-pulmonary shunt. Both of these patients subsequently died. There was one completion of Fontan circulation for an unbalanced CAVSD and this patient continues to do well.

\section{Eisenmenger's syndrome}

Eighteen of the 342 (5\%) patients were diagnosed with Eisenmenger's syndrome. In the majority of cases this diagnosis was based on clinical and echocardiographic findings with a small minority of patients undergoing cardiac catheterisation. These patients were all born in the first era of study

Table 1 Surgical results by era

\begin{tabular}{lllll}
\hline Years & $\begin{array}{l}\text { Total number } \\
\text { of patients }\end{array}$ & $\begin{array}{l}\text { Number of patients } \\
\text { operated on }\end{array}$ & $\begin{array}{l}\text { Overall } \\
\text { mortality }\end{array}$ & $\begin{array}{l}\text { Early postoperative } \\
\text { mortality (30-day) }\end{array}$ \\
\hline $1985-1995$ & 162 & $101(62 \%)$ & $30 \%$ & $14.0 \%$ \\
$1996-2006$ & 180 & $129(72 \%)$ & $5 \%$ & $1.5 \%$ \\
\hline
\end{tabular}

Figure 1 Number of infants live born with Down's syndrome per year: total live births and those with a cardiovascular anomaly. 


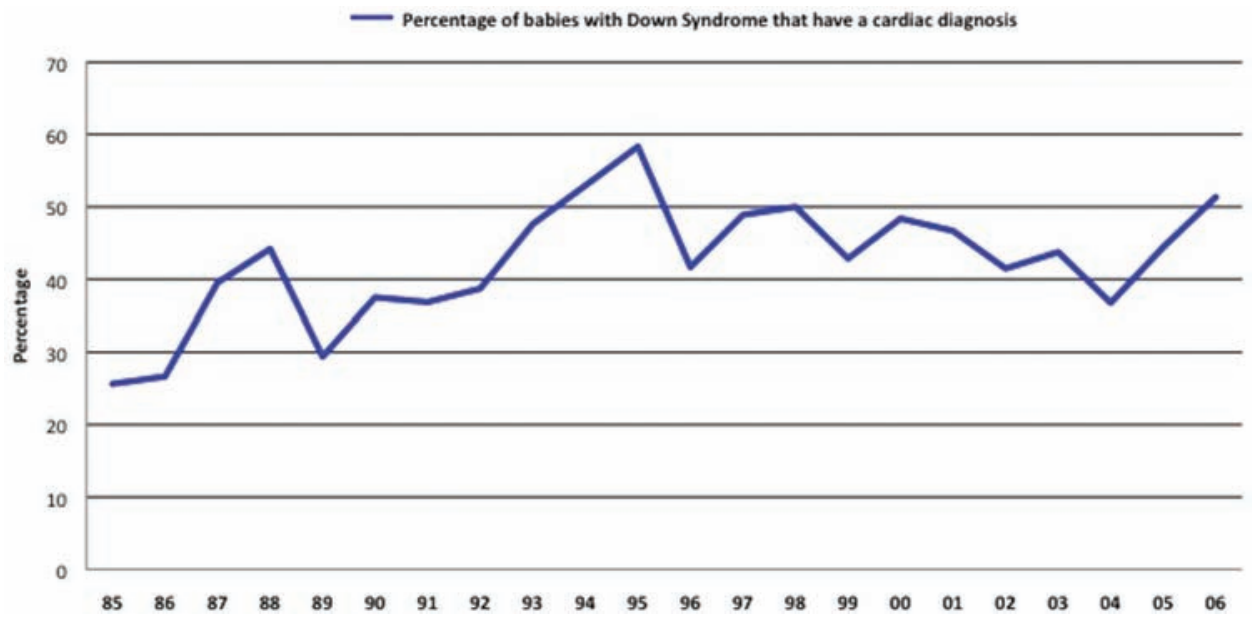

Figure 2 Percentage of infants live born with Down's syndrome and a cardiovascular anomaly.

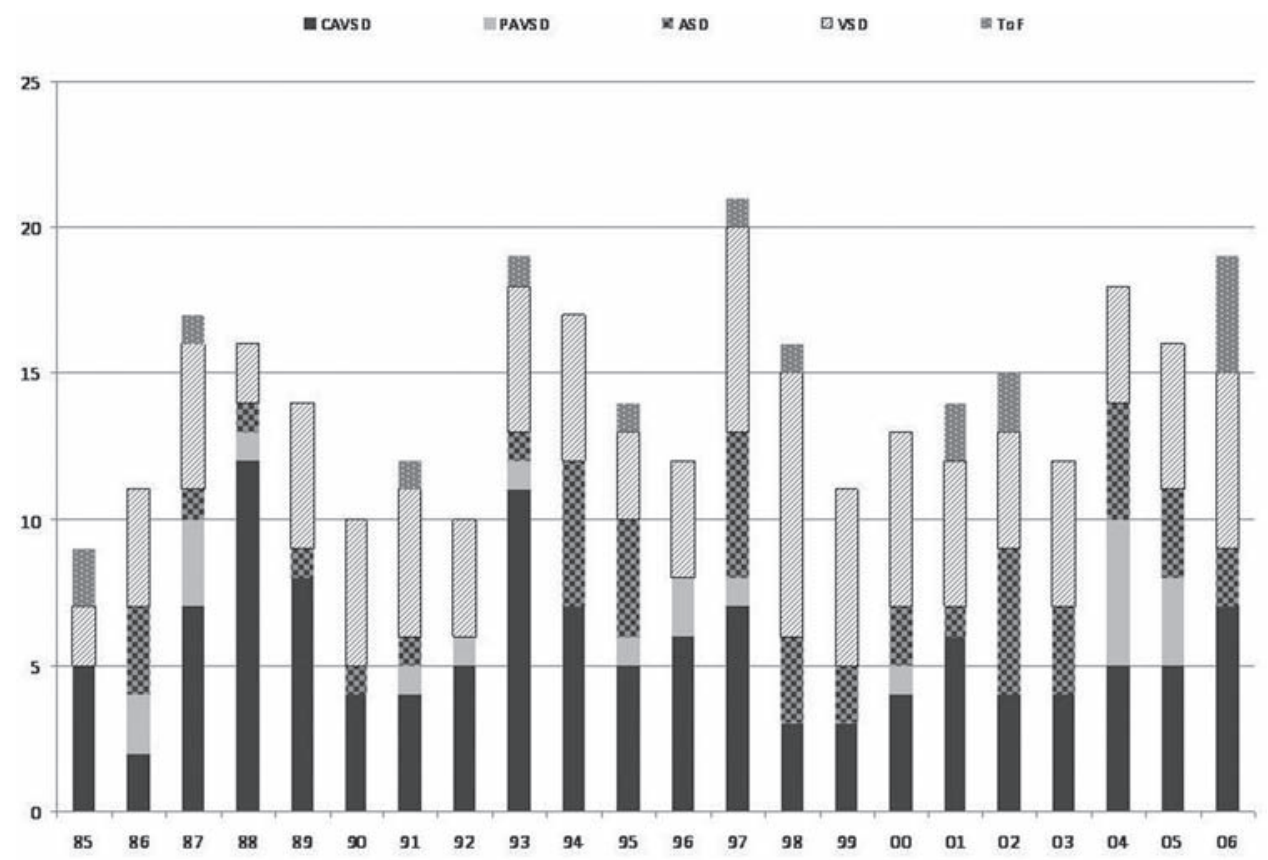

Figure 3 The distribution over time of the five main diagnostic groups. ASD, atrial septal defect; CAVSD, complete atrioventricular septal defect; PAVSD, partial atrioventricular septal defect; ToF, tetralogy of Fallot; VSD, ventricular septal defect.

(1985-1995). Diagnoses were CAVSD in 12 patients, VSD in four, PAVSD in one and PDA in one. Two of these patients had palliation with pulmonary artery banding. None underwent corrective surgery. Ten of these 18 patients subsequently died (56\%).

No children with Down's syndrome have presented with primary pulmonary hypertension without an underlying cardiovascular anomaly.

\section{Cardiac transplantation}

Two patients underwent cardiac transplantation for dilated cardiomyopathy secondary to anthracycline-containing chemotherapy. The first was 11.1 years of age at the time of transplant and continues to do well 5.6 years later with no significant problems. The second patient presented acutely at 3 years of age with end stage cardiac failure (transplanted at 3.4 years of age). She required prolonged inotropic support and following an acute deterioration was placed on a Berlin
Heart Excor biventricular assist device. She received an $\mathrm{ABO}-$ incompatible heart transplant due to her low anti-A and anti-B isohaemagglutinins and, apart from recurrent chest infections, is well at 3.1 years post transplant with no episodes of rejection and normal coronary angiography.

\section{Survival}

There were 66 deaths in patients with Down's syndrome and a cardiovascular anomaly in the study period (19\%). The mean age at death was 1.3 years (0-11.9 years) with 46 deaths $(70 \%$ of deaths) occurring in infancy.

One-year survival in Down's syndrome with a cardiac diagnosis has improved over time from $82 \%$ in 1985-1995 to $94 \%$ in 1996-2006 (figure 4).

\section{DISCUSSION}

This study has shown a prevalence of cardiovascular anomalies in Down's syndrome of $42 \%$ in keeping with other published 


\section{Survival by era}

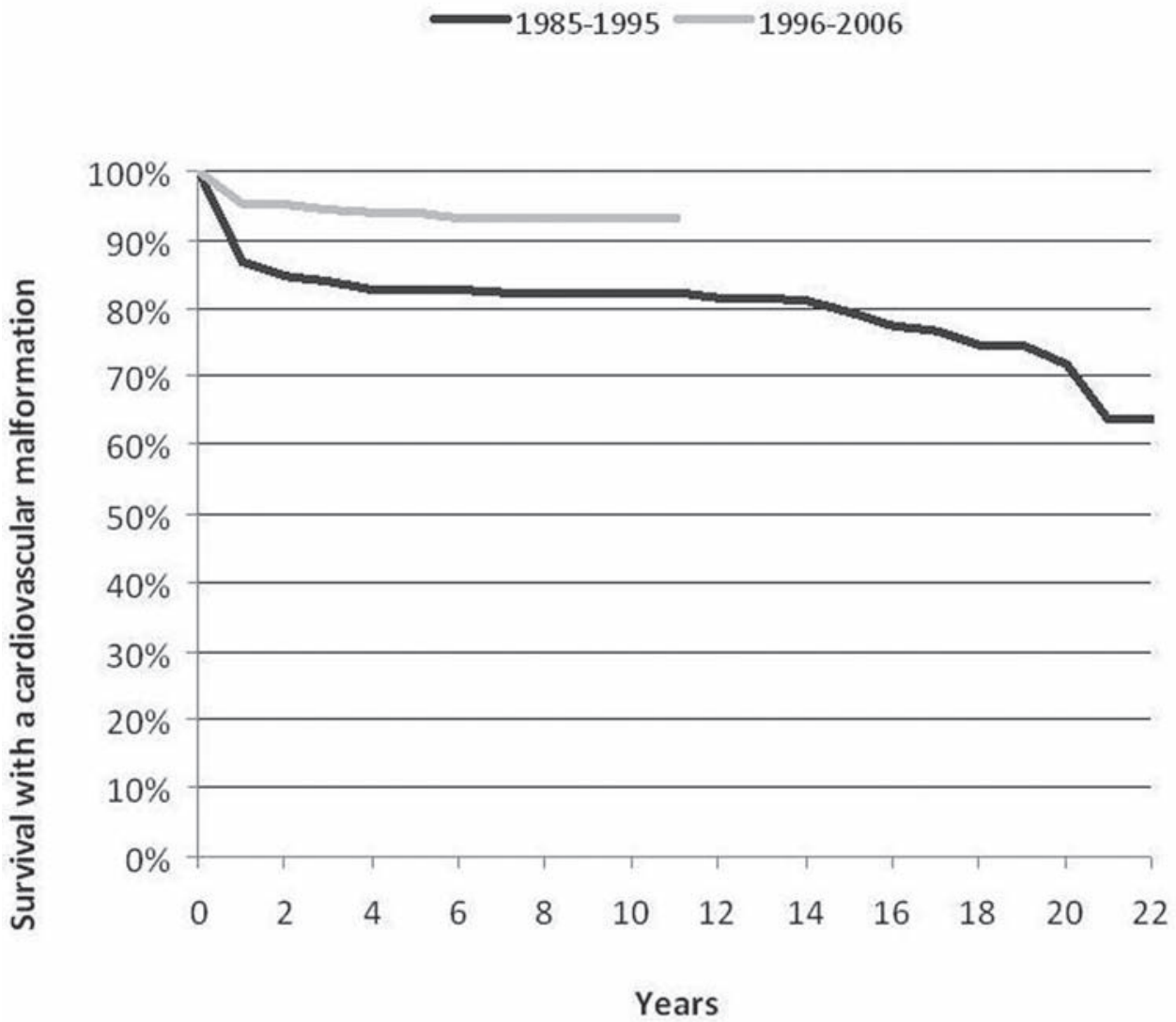

Figure 4 Long term survival with Down's syndrome and a cardiovascular anomaly.

reports. ${ }^{8-10}$ Prevalence has remained relatively unchanged over time, although it does appear to be increasing in recent years. This may be due to improved diagnosis and the more widespread use of routine echocardiographic screening for infants with Down's syndrome. ${ }^{11}$ There has also been an increase in prenatal diagnosis of Down's syndrome, ${ }^{12}{ }^{13}$ and the use of fetal echocardiography. ${ }^{14} 15$

The North East of England is well suited for populationbased studies as it encompasses a well-defined geographical area with little cross-referral, reducing the risks of ascertainment bias. Data from our region have previously shown an increase in the prevalence of pregnancies affected by Down's syndrome and that, contrary to previous predictions, the prevalence of live born Down's syndrome has remained static, with a live birth prevalence of around 1.09 per 1000 live births. ${ }^{4}$ These babies all require screening echocardiography for the detection of congenital heart disease.

The cardiovascular anomalies affecting children with Down's syndrome are usually amenable to curative surgical intervention and CAVSD has remained the commonest form of congenital heart disease in this population. This is in keeping with reports from other countries such as the United States, ${ }^{2}$ Guatemala9 and Oman. ${ }^{8}$ Early diagnosis is preferable and therefore screening echocardiography is routinely performed in many centres. The incidence of univentricular physiology is low, but it is difficult to speculate on the basis of our data as to whether this is a reflection simply of the fact that these abnormalities are relatively rare in the Down's syndrome population or whether it is due to improved antenatal diagnosis and subsequent termination of pregnancies with more severe abnormalities. In fact, one of the limitations of this study is that we have not reviewed the association between those pregnancies undergoing termination and congenital heart disease as these details were not reliably available. Further limitations of our study include a lack of catheter and echocardiographic data on the patients who developed Eisenmenger's syndrome and the fact that accurate data on cause of late death were not available for analysis.

Many children with Down's syndrome are affected by other problems such as co-existing respiratory conditions. Poor respiratory function needs to be considered when contemplating total cavopulmonary connection (Fontan circulation) for the palliation of single ventricle physiology in these patients. In our institution, the patient who underwent a completion of Fontan circulation for an unbalanced CAVSD has done well and, as detailed in previous studies, Down's syndrome is no longer a barrier to this procedure. ${ }^{16}$

Two patients in our series underwent successful cardiac transplantation, and this was for acquired dilated cardiomyopathy rather than for structural heart disease. In the past, a diagnosis of Down's syndrome precluded assessment for transplantation, but this is no longer the case and our experience with transplantation in Down's syndrome has been good.

Treatment options for congenital heart disease and results of surgical correction continue to improve. There has been a significant reduction in peri-operative mortality and an increase in survival in all patients with cardiovascular anomalies over the last two decades. ${ }^{1} 101718$ In our study, overall mortality post 
surgery in patients with Down's syndrome decreased from $30 \%$ to $5 \%$, with an almost 10 -fold decrease in early postoperative mortality. This is in keeping with the improvement in overall surgical outcomes, with contributing factors possibly being advances in technical surgical expertise and postoperative care. Improvements in all areas of cardiac and general medical care have led to a significant improvement in long term survival over time with most patients now expected to survive into adulthood. Multidisciplinary care is now a routine part of management of these patients both in infancy and later in life.

There is now an increasing population of adults with congenital heart disease ${ }^{19}$ and a correspondingly large number of older children and adult patients with Down's syndrome ${ }^{20}$ who have undergone surgical correction of cardiovascular anomalies. Resources need to be made available for the overall and lifelong care of these patients and prenatal and genetic counselling of these families is also of utmost importance. Down's syndrome in and of itself is no longer a barrier to surgical treatment of more complex congenital heart disease and cardiac transplantation may be considered in appropriate patients. Knowledge of the types and outcomes of cardiovascular anomalies is of importance not only to cardiologists, paediatricians and general practitioners but also to obstetricians and specialists in fetal medicine who are involved in counselling prospective patients of an infant with Down's syndrome and a cardiac problem.

\section{Competing interests None.}

Ethics approval This study was conducted with the approval of NorCAS. The National Information Governance Board has granted exemption from a requirement for consent for inclusion on the NorCAS register. NorCAS has ethics approval (04/MRE04/25) to undertake studies involving the use of its data.

Provenance and peer review Not commissioned; externally peer reviewed.

\section{REFERENCES}

1. Tennant PW, Pearce MS, Bythell M, et al. 20-year survival of children born with congenital anomalies: a population-based study. Lancet 2010;375:649-56.
2. Freeman SB, Taft LF, Dooley KJ, et al. Population-based study of congenital heart defects in Down syndrome. Am J Med Genet 1998;80:213-17.

3. Wells GL, Barker SE, Finley SC, et al. Congenital heart disease in infants with Down's syndrome. South Med J 1994;87:724-7.

4. Irving C, Basu A, Richmond S, et al. Twenty-year trends in prevalence and survival of Down syndrome. Eur J Hum Genet 2008;16:1336-40.

5. Bell R, Rankin J, Donaldson LJ. Down's syndrome: occurrence and outcome in the north of England, 1985-99. Paediatr Perinat Epidemiol 2003;17:33-9.

6. McElhinney DB, Wernovsky G. Outcomes of neonates with congenital heart disease. Curr Opin Pediatr 2001;13:104-10.

7. Dolk H. EUROCAT: 25 years of European surveillance of congenital anomalies. Arch Dis Child Fetal Neonatal Ed 2005;90:F355-8.

8. Jaiyesimi 0, Baichoo V. Cardiovascular malformations in Omani Arab children with Down's syndrome. Cardiol Young 2007;17:166-71.

9. Vida VL, Barnoya J, Larrazabal LA, et al. Congenital cardiac disease in children with Down's syndrome in Guatemala. Cardiol Young 2005;15:286-90.

10. Lin $\mathbf{A E}$, Basson CT, Goldmuntz E, et al. Adults with genetic syndromes and cardiovascular abnormalities: clinical history and management. Genet Med 2008;10:469-94.

11. McElhinney DB, Straka M, Goldmuntz E, et al. Correlation between abnormal cardiac physical examination and echocardiographic findings in neonates with Down syndrome. Am J Med Genet 2002;113:238-41.

12. Morris JK. The National Down Syndrome Cytogenetic Register 2007/2008 Annual Report. London: Barts and the London School of Medicine and Dentistry. Queen Mary University of London, 2009. http://www.wolfson.qmul. ac.uk/ndscr/

13. Shipp TD, Benacerraf BR. Second trimester ultrasound screening for chromosomal abnormalities. Prenat Diagn 2002;22:296-307.

14. Abu-Harb M, Wyllie J, Hey E, et al. Antenatal diagnosis of congenital heart disease and Down's syndrome: the potential effect on the practice of paediatric cardiology. Br Heart J 1995;74:192-8.

15. Gardiner H. Fetal echocardiography: 20 years of progress. Heart 2001;86 (Suppl II):iii2-22.

16. Campbell RM, Adatia I, Gow RM, et al. Total cavopulmonary anastomosis (Fontan) in children with Down's syndrome. Ann Thorac Surg 1998;66:523-6.

17. Dadvand P, Rankin J, Shirley MD, et al. Descriptive epidemiology of congenital heart disease in Northern England. Paediatr Perinat Epidemiol 2009;23:58-65.

18. Frid C, Drott $P$, Lundell $B$, et al. Mortality in Down's syndrome in relation to congenital malformations. J Intellect Disabil Res 1999;43(Pt 3):234-41.

19. Wren C, O'Sullivan JJ. Survival with congenital heart disease and need for follow up in adult life. Heart 2001;85:438-43.

20. Hayes C, Johnson Z, Thornton L, et al. Ten-year survival of Down syndrome births. Int J Epidemiol 1997;26:822-9. 